Математическое моделирование теплофизических процессов в стенке кисты Бейкера, при нагреве внутрикистозной жидкости лазерным излучением длиной волны 1.47 мкм

\author{
С. А. Чернядьев ${ }^{1}$, А. В. Жиляков ${ }^{2, a}$, В. И. Горбатов ${ }^{3}$, Н. Ю. Коробова ${ }^{2}$, \\ Н. И. Сивкова ${ }^{4}$, А. В. Аретинский ${ }^{5}$ А. И. Чернооков ${ }^{6}$ \\ ${ }^{1}$ ГБОУ ВПО «Уральский государственный медицинский университет» Минздрава России, \\ Россия, 620000, г. Екатеринбург, ул. Репина, д. 3 \\ ${ }^{2}$ ГАУ здравоохранения Свердловской области \\ «Областной специализированный центр медицинской реабилитации “Озеро Чусовское”», \\ Россия, 620053, г. Екатеринбург, п. Чусовское Озеро, ул. Мира, д. 1 \\ ${ }^{3}$ ФГБОУ ВО «Уральский государственный горный университет», \\ Россия, 620144, г. Екатеринбург, ул. Куйбышева, д. 30 \\ ${ }^{4}$ ФГАОУ ВПО «УрФУ имени первого Президента России Б. Н. Ельцина», \\ Россия, 620002, г. Екатеринбург, ул. Мира, д. 19 \\ ${ }^{5}$ ООО «ПЭТ-Технолоджи» ОП, Россия, 620036, г. Екатеринбург, ул. Соболева, д. 29, стр. 8 \\ 6 ЗАО «Центр Флебологии», 119002, г. Москва, пер. Сивцев Вражек, д. 45, стр. 1 \\ E-mail: a doctor-zhilyakov@rambler.ru
}

Получено 21.08.2017, после доработки - 19.01.2018.

Принято к публикаџии 24.01.2018.

Работа посвящена теоретическому изучению величины деструктивного влияния на нормальные ткани организма инфракрасным излучением, выходящим за пределы обрабатываемого патологического очага. Такая ситуация возможна при сверхдлительном воздействии прямого лазерного излучения на биоткани. Решением этой проблемы может служить равномерное распределение тепла внутри объема через опосредованное нагревание жидкости, что способствует минимальному повреждению перифокальных структур. Представлена нестационарная теплофизическая модель процесса распространения тепла в биотканях, позволяющая проводить исследования передачи энергии от внутреннего жидкого содержимого кисты Бейкера, нагреваемого инфракрасным лазерным излучением заданной удельной мощности, через определенную толщину ее стенки к окружающим биологическим тканям. Расчет пространственно-временного распределения температуры в стенке кисты и окружающей жировой ткани осуществляется конечно-разностным методом. Время эффективного воздействия температуры на всю толщину стенки кисты оценивалось достижением $55^{\circ} \mathrm{C}$ на ее наружной поверхности. Безопасность процедуры обеспечивает длительность экспозиции данной величины не более 10 секунд.

В результате проведенных вычислений установлено, что имеются несколько режимов работы хирургического лазера, соответствующих всем требованиям безопасности при одновременной эффективности процедуры. Локальная односторонняя гипертермия синовиальной оболочки и последующая коагуляция всей толщины стенки за счет переноса тепла способствуют ликвидации полостного новообразования подколенной области. При ее толщине 3 мм удовлетворительным является режим нагрева, при котором время воздействия длится около 200 секунд, а удельная мощность лазерного излучения во внутренней среде жидкостного содержимого кисты Бейкера составляет примерно 1 Вт/г.

Ключевые слова: математическая аналогия, биологическая ткань, теплопередача, теплоемкость, киста Бейкера, моделирование процесса, термокоагуляция

Работа выполнена при финансовой поддержке за счет средств гранта по программе «Старт-1», выданного Федеральным государственным бюджетным учреждением «Фонд содействия развитию малых форм предприятий в научнотехнической сфере» (Фонд содействия инновациям).

(c) 2018 Сергей Александрович Чернядьев, Андрей Викторович Жиляков, Владимир Иванович Горбатов, Наталья Юрьевна Коробова, Надежда Ивановна Сивкова, Александр Витальевич Аретинский, Александр Иванович Чернооков 
UDC: $616.768 .3-006.38$

\title{
Mathematical modeling of thermophysical processes in the wall of the Baker cyst, when intra-cystic fluid is heated by laser radiation $1.47 \mu \mathrm{m}$ in length
}

\author{
S. A. Chernjad'ev', A. V. Zhiljakov ${ }^{2, a}$, V. I. Gorbatov ${ }^{3}$, N. Yu. Korobova ${ }^{2}$, \\ N. I. Sivkova ${ }^{4}$, A. V. Aretinsky ${ }^{5}$, A. I. Chernookov6 \\ ${ }^{1}$ State Medical University of Higher Professional Education "Ural State Medical University", \\ Ministry of Health of the Russian Federation, Repina st. 3, Ekaterinburg, 620000, Russia \\ ${ }^{2}$ GAU of public health services of Sverdlovsk region \\ "The regional specialized center of medical rehabilitation "Lake Chusovskoe", \\ Mira st. 1, village Chusovskoe Ozero, Ekaterinburg, 620053, Russia \\ ${ }^{3}$ Federal State Budget Educational Educational Institution of Higher Education \\ "Ural State Mining University" (FGBOU IN UGGU), \\ Kuibyshev st. 30, Ekaterinburg, 620144, Russia \\ ${ }^{4}$ FGAOU VPO "UrFU named after the first President of Russia B. N. Yeltsin", \\ Mira st. 19, Ekaterinburg, 620002, Russia \\ ${ }^{5}$ OOO “PET - Technology" OP, Soboleva st. 29/8, Ekaterinburg, 620036, Russia \\ ${ }^{6}$ Closed Joint Stock Company "Center of Phlebology”, per. Sivcev Vrazhek 45/1, Moscow, 119002, Russia
}

E-mail: ${ }^{a}$ doctor-zhilyakov@rambler.ru

Received 21.08.2017, after completion - 19.01.2018. Accepted for publication 24.01.2018.

The work is devoted to the study of the theoretical value of destructive influence on normal tissues of an organism by infrared radiation that goes beyond the treated pathological focus. This situation is possible if the direct laser radiation on the tissues is extremely long-acting. The solution to this problem can be the uniform distribution of heat inside the volume through indirect heating of the liquid, which contributes to minimal damage to the perifocal structures. A non-stationary thermophysical model of the process of heat propagation in biological tissues is presented, allowing to carry out studies of energy transfer from internal liquid contents of Baker's cyst heated by infrared laser radiation of a given specific power through a certain thickness of its wall to surrounding biological tissues. Calculation of the spacetime temperature distribution in the cyst wall and surrounding fat tissue is carried out by the finite-difference method. The time of effective exposure to temperature on the entire thickness of the cyst wall was estimated to be $55^{\circ} \mathrm{C}$ on its outer surface. The safety procedure ensures the exposure duration of this value is not more than 10 seconds.

As a result of the calculations carried out, it is established that there are several operating modes of a surgical laser that meet all the safety requirements with a simultaneous effective procedure. Local one-sided hyperthermia of the synovial membrane and subsequent coagulation of the entire wall thickness due to heat transfer contributes to the elimination of the cavity neoplasm of the popliteal region. With a thickness of $3 \mathrm{~mm}$, the heating mode is satisfactory, under which the exposure time lasts about 200 seconds, and the specific power of the laser radiation in the internal medium of the liquid contents of the Baker cyst is approximately 1.

Keywords: mathematical analogy, biological tissue, heat transfer, heat capacity, Baker's cyst, process modeling, thermocoagulation

Citation: Computer Research and Modeling, 2018, vol. 10, no. 1, pp. 103-112 (Russian).

The work was supported by at the expense of the grant under the "Start-1" program, issued by the Federal State Budgetary Institution "Fund for Assistance to Small Innovative Enterprises in the Scientific and Technical Sphere" (Innovation Promotion Fund). 
Современную амбулаторную хирургию невозможно себе представить без малоинвазивных термодеструктивных вмешательств, направленных на ликвидацию патологических тканей. Здесь можно выделить два типа вмешательств: криовоздействие, основанное на применении низких температур [Гарюк, 2016; Mahmudovich, 2016], и, в противоположность ему, хирургию высоких температур.

Наиболее известными способами локального нагрева являются лазерное и электротермическое воздействие. Открытые и визуально контролируемые операции, проводимые с применением ИК-лазеров, бескровны и безболезненны. Однако ситуация на сегодняшний день такова, что внедрение новых технологий интерстициального воздействия на биоткани значительно опережает накопление фундаментальных знаний о вызываемых теплофизических и биологических процессах [Галиулин, 2016; Kumar, 2016]. Это ограничивает применение локального нагрева и не позволяет получить оптимальный эффект в медицинской практике при отсутствии рисков нежелательных последствий. В настоящее время идет активный набор экспериментальных данных по изменению свойств биотканей полостных образований. При этом в качестве теплоносителя применяется собственный экссудат или введенная извне жидкость. Применение лазеров «водопоглащающего» спектра в водной среде ограничит фотодеструктивное действе лазерного излучения за счет высокой степени поглощения, которое, в свою очередь, повысит КПД нагрева теплоотдающей среды [Чудновский, 2016].

Однако до сих пор неизвестными остаются необходимая удельная мощность лазерного излучения и скорость нагрева теплонесущей жидкости, достаточной для необратимой коагуляции всех слоев капсулы образования. В то же время требуется максимально щадящий тепловой режим для близкорасположенных анатомических структур.

Цель данной работы - смоделировать термодинамические процессы, происходящие при термическом одностороннем равномерном нагреве соединительных тканей кисты Бейкера, и продемонстрировать, что такой метод позволяет количественно и качественно предсказать поведение неизмененных окружающих кисту тканей в том или ином режиме локального гидротермического нагрева.

Предположено, что внутрь кисты с толщиной стенки $\delta_{1}=3$ мм вводится термонесущая жидкость (вода) с начальной температурой $T=297 \mathrm{~K}\left(24{ }^{\circ} \mathrm{C}\right)$, которая затем нагревается инфракрасным лазерным излучением ( $\lambda=1.47$ мкм) до температуры коагуляции биотканей, равной $343 \mathrm{~K}\left(70{ }^{\circ} \mathrm{C}\right)$. Снаружи киста окружена жировой тканью толщиной $\delta_{2}=7$ мм. Для наглядности предлагаемой модели на рис. 1 представлен срез кисты Бейкера, взятый из работы [Determination of the Factors..., 2012] и адаптированный к теме данной статьи.

Для практических задач термохирургии требуется определить время, необходимое для прогрева стенки кисты при разных объемах термонесущей жидкости $(2,5,10$ мл) и мощностях лазерного излучения $(2,5,10 \mathrm{BT})$ при условии, что температура

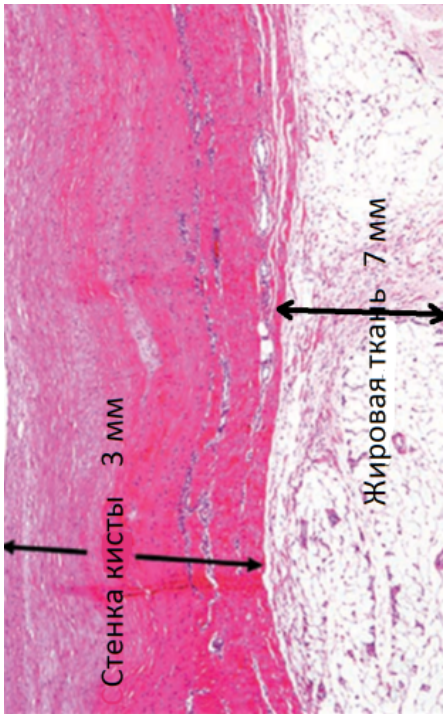

Рис. 1. Поперечный срез стенки кисты Бейкера и окружающих тканей

жировой ткани в месте контакта не будет превышать $56-58{ }^{\circ} \mathrm{C}$ в течение 10 секунд с момента достижения температуры коагуляции коллагена на внутренней поверхности кисты. Это время необходимо для предотвращения запуска необратимых процессов в биотканях, поскольку в жировой клетчатке располагаются большеберцовый и общий малоберцовый нервы, а также поколенная вена и артерия, прилегающие к капсуле коленного сустава [Петровский, 1974].

Ввиду сложности исходной теплофизической задачи ее общее решение можно разбить на два этапа с различными упрощающими допущениями.

Известно, что эффект теплового воздействия на биоткань зависит от пространственновременной динамики изменения ее температуры в процессе нагрева. В нашем случае эта дина- 
мика будет определяться в основном длительностью нагрева термонесущей жидкости. Поэтому на первом этапе рассмотрим процесс нагрева жидкости массой $m_{f}$ и удельной теплоемкостью $c_{p f}$ от начальной температуры $T_{0 f}$ до температуры коагуляции коллагена $T_{c o g}\left(70{ }^{\circ} \mathrm{C}\right)$.

Согласно закону сохранения энергии для введенного внутрь кисты объема жидкости можно записать так:

$$
c_{p f} m_{f} \frac{\partial T_{f}}{\partial \tau}=P_{0}-Q_{\tau}
$$

где $P_{0}$ - мощность подводимого лазерного излучения, $Q_{\tau}=q S$ - тепловой поток через внутреннюю поверхность стенки кисты, ограничивающую данный объем жидкости, $q$ - плотность теплового потока, $S$ - площадь поверхности.

Допустим, что нагрев осуществляется равномерно по всему объему жидкости, т. е. предполагаем, что процесс локального поглощения излучения лазера сопровождается интенсивным конвективным перемешиванием. Тогда скорость изменения температуры жидкости будет равна

$$
\mathrm{v}_{T}=\frac{\partial T_{f}}{\partial \tau}=\frac{P_{0}-Q_{\tau}}{c_{p f} m_{f}}
$$

Величина $Q_{\tau}$, входящая в соотношение (2), на данном этапе решения задачи не поддается определению, поскольку зависит от геометрии полости (площади поверхности) и плотности теплового потока в окружающую ее стенку, который, в свою очередь, зависит от температурного напора и коэффициента теплоотдачи $\alpha$ по закону

$$
q=\alpha\left(T-T_{f}\right) .
$$

Коэффициент теплоотдачи - сложная величина, и ее невозможно определить общей формулой. Обычно $\alpha$ находится экспериментально.

Однако, учитывая небольшую теплопроводность стенки кисты, можно с высокой долей вероятности предположить, что в процессе нагрева термонесущей жидкости температура поверхности стенки кисты будет мало отличаться от температуры жидкости. Кроме того, в первом приближении будем считать, что эта температура изменяется во времени по линейному закону. Тогда время, необходимое для нагрева термонесущей жидкости от начальной температуры $T_{0 f}$ до температуры $T_{c o g}$, можно оценить по формуле

$$
\tau_{c}=\frac{c_{p f}\left(T_{c o g}-T_{0 f}\right)}{P_{m}}
$$

где $P_{m}=k \cdot P_{0} / m_{f}$ - удельная мощность источника тепла [Вт/кг], которая расходуется только на нагрев заданной массы жидкости. Это время $\tau_{c}$ в дальнейшем будем называть временем воздействия.

Поправочный коэффициент определяется соотношением

$$
k=\frac{P_{0}-\left\langle Q_{\tau}\right\rangle}{P_{0}},
$$

где $\left\langle Q_{\tau}\right\rangle=\frac{1}{\tau_{c}} \int_{0}^{\tau_{c}} Q_{\tau} d \tau-$ средний за время воздействия тепловой поток, который учитывает долю мощности лазерного излучения, идущего на нагрев окружающих жидкость биотканей. 
На втором этапе решения задачи рассчитаем нестационарные температурные поля $T(x, \tau)$ в системе «стенка кисты - жировая ткань» (рис. 2) и плотность теплового потока $q$ на границе $x=0$ в предположении, что изменение температуры на внутренней поверхности кисты в каждый момент времени совпадает с температурой термонесущей жидкости.

Для определения температуры в любой момент времени и в любой точке исследуемой системы воспользуемся одномерным нестационарным уравнением теплопроводности:

$$
c_{p i} \rho_{i} \frac{\partial T}{\partial \tau}=\frac{\partial}{\partial x}\left[\lambda_{i} \frac{\partial T}{\partial x}\right],
$$

а для расчета плотности теплового потока — законом Фурье:

$$
q=\lambda_{i} \frac{\partial T}{\partial x},
$$

где $\rho_{i}-$ плотность, $\lambda_{i}-$ коэффициент теплопроводности,

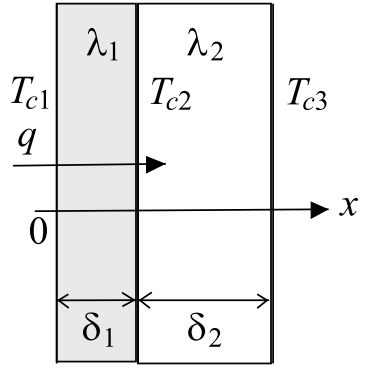

Рис. 2. Геометрическая и теплофизическая модель объекта «стенка кисты - жировая ткань»: $\delta_{1}$ и $\lambda_{1}-$ толщина и теплопроводность стенки кисты, $\delta_{2}$ и $\lambda_{2}-$ толщина и теплопроводность стенки жировой ткани, $q$ - плотность теплового потока, $T_{c 1}, T_{c 2}, T_{c 3}$ - температура на границах модели $c_{p i}$ - удельная теплоемкость при постоянном давлении, $i=1$ обозначает свойства кисты, $i=2$ обозначает свойства жировой ткани.

Предполагаем, что плотность и теплофизические свойства стенки кисты и жировой ткани не зависят от температуры. При расчетах не будем также учитывать интенсивность кровотока в жировой ткани ввиду его незначительности.

Начальная температура исследуемого объекта принимается равной нормальной температуре человеческого тела - $309.6 \mathrm{~K}\left(36.6^{\circ} \mathrm{C}\right)$, начальная температура термонесущей жидкости - $T_{0 f}=297 \mathrm{~K}\left(24^{\circ} \mathrm{C}\right)$.

Граничные условия задаются следующим образом:

a) температура поверхности кисты $T_{c 1}$ на границе $x=0$ вначале изменяется во времени по линейному закону:

$$
T_{c 1}(\tau)=T_{0 f}+\frac{T_{c o g}-T_{0 f}}{\tau_{c}} \tau,
$$

а затем, по истечению времени воздействия $\tau_{c}$, остается постоянной и равной $T_{c o g}$;

б) температура $T_{c 3}$ на внешней поверхности жировой ткани $x=\delta_{1}+\delta_{2}$ постоянна во времени и равна 309.6 К $\left(36.6^{\circ} \mathrm{C}\right)$, т. е. предполагается, что примыкающие к ней биологические ткани снабжены кровотоком;

в) в месте соприкосновения слоев $x=\delta_{1}$ соблюдается идеальный тепловой контакт.

Для приближенного решения поставленной краевой задачи теплопроводности применен метод конечных разностей. При построении разностного аналога задачи используется интегроинтерполяционный метод (метод баланса) [Беляев, 1982]. Его преимущество заключается в том, что разностные уравнения строятся на основе интегральных соотношений, выражающих закон сохранения энергии для каждой элементарной ячейки пространственно-временной сетки, на которую разбивается область непрерывного изменения аргументов. Полученная в результате таких преобразований система разностных линейных уравнений решается с помощью ЭВМ методом прогонки. На каждом временном шаге определяются температуры в узловых точках пространственной сетки и плотности тепловых потоков через элементарные ячейки сетки.

Необходимые для расчетов исходные данные по теплофизическим свойствам термонесущей жидкости и биотканям взяты нами из справочной литературы и представлены в таблице 1. 
Таблица 1. Теплофизические свойства биотканей и термонесущей жидкости

\begin{tabular}{|c|c|c|c|}
\hline Вид биоткани/жидкости & 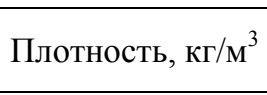 & $\begin{array}{c}\text { Удельная теплоемкость, } \\
\text { Дж/(кг } \cdot \text { К) } \\
\end{array}$ & $\begin{array}{c}\text { Коэффициент теплопро- } \\
\text { водности, Вт/(м · К) }\end{array}$ \\
\hline Фиброзная & 1027 & 2372 & 0,39 \\
\hline Жировая & 911 & 2348 & 0,2 \\
\hline Вода & 1000 & 4220 & 0,68 \\
\hline
\end{tabular}

Поскольку в начале расчетов поправочный коэффициент $k$ в формуле (3) неизвестен, то мы приняли его равным единице. Это допущение позволяет оценить минимальное время воздействия $\tau_{\min }$, которое соответствует в пределе адиабатическому режиму нагрева термонесущей жидкости.

Результаты расчетов минимального времени воздействия для различных соотношений массы воды и мощности лазерного излучения представлены в таблице 2.

Таблица 2. Минимальное время воздействия, соответствующее различным комбинациям объемов термонесущей жидкости $(2,5,10$ мл) и мощности лазерного излучения $(2,5,10$ Вт)

\begin{tabular}{|l|c|c|c|c|c|c|}
\hline$P_{m}=P_{0} / m_{f}, \mathrm{BT} / \Gamma$ & 0.2 & 0.4 & 1 & 2 & 2.5 & 5 \\
\hline$\tau_{\min }, \mathrm{c}$ & 960 & 480 & 200 & 100 & 80 & 40 \\
\hline
\end{tabular}

На рис. 3 представлены результаты оценки пространственного распределения температуры в стенке кисты (3 мм) и окружающей ее жировой ткани (7 мм) для нескольких значений удельной мощности в моменты времени $\tau_{\min }$ (см. таблицу 2 ).

Видно, что при малых значениях удельной мощности $\left(P_{m}<1\right.$, кривые 1 и 2$)$ распределение температуры в стенке кисты $(0<x<3$ мм) и жировой ткани $(3<x<10$ мм) практически линейно. Перепад температур по толщине стенки кисты составляет не более $10{ }^{\circ} \mathrm{C}$. Однако температура жировой ткани в месте контакта уже превышают критическую величину $56-58{ }^{\circ} \mathrm{C}$, что приведет к необратимым изменениям в жировой ткани. Отсюда следует, что данный режим теплового воздействия на термонесущую жидкость нежелателен.

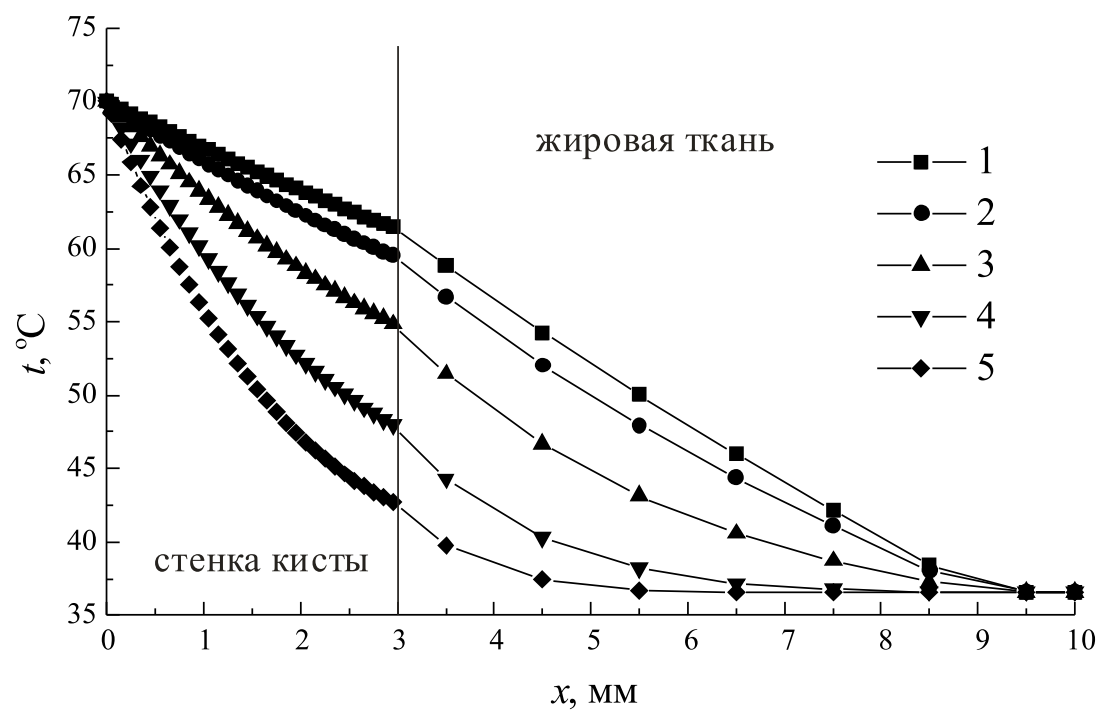

Рис. 3. Пространственное распределение (по координате $x$ ) температуры $t$ в сечении «киста - жировая ткань» в момент времени, когда температура термонесущей жидкости достигнет значения $70{ }^{\circ} \mathrm{C}$ при различных значениях подводимой удельной мощности: $1-P_{m}=0.2,2-P_{m}=0.4,3-P_{m}=1$, $4-P_{m}=2.5,5-P_{m}=5(\mathrm{BT} / \Gamma)$ 
С увеличением скорости нагрева термонесущей жидкости $\left(P_{m}>1\right.$, кривые 4 и 5$)$ температура в месте контакта и прилежащих областях во всех случаях не превышает $50{ }^{\circ} \mathrm{C}$, т. е. жировая ткань находится в зоне некритичных температур. В то же время перепад температур по толщине кисты таков, что процесс необратимой коагуляции в стенке кисты остается незавершенным. Следовательно, нужно рассмотреть динамику изменения температуры в последующие моменты времени.

На рис. 4 представлены результаты расчета динамики изменения температуры на границе «стенка кисты - жировая ткань» для трех значений времени воздействия. Здесь же для сравнения приведена зависимость температуры от времени (кривая 1) для случая, когда во внутреннюю полость кисты сразу же вводится жидкость с начальной температурой, равной $T_{c o g}$.

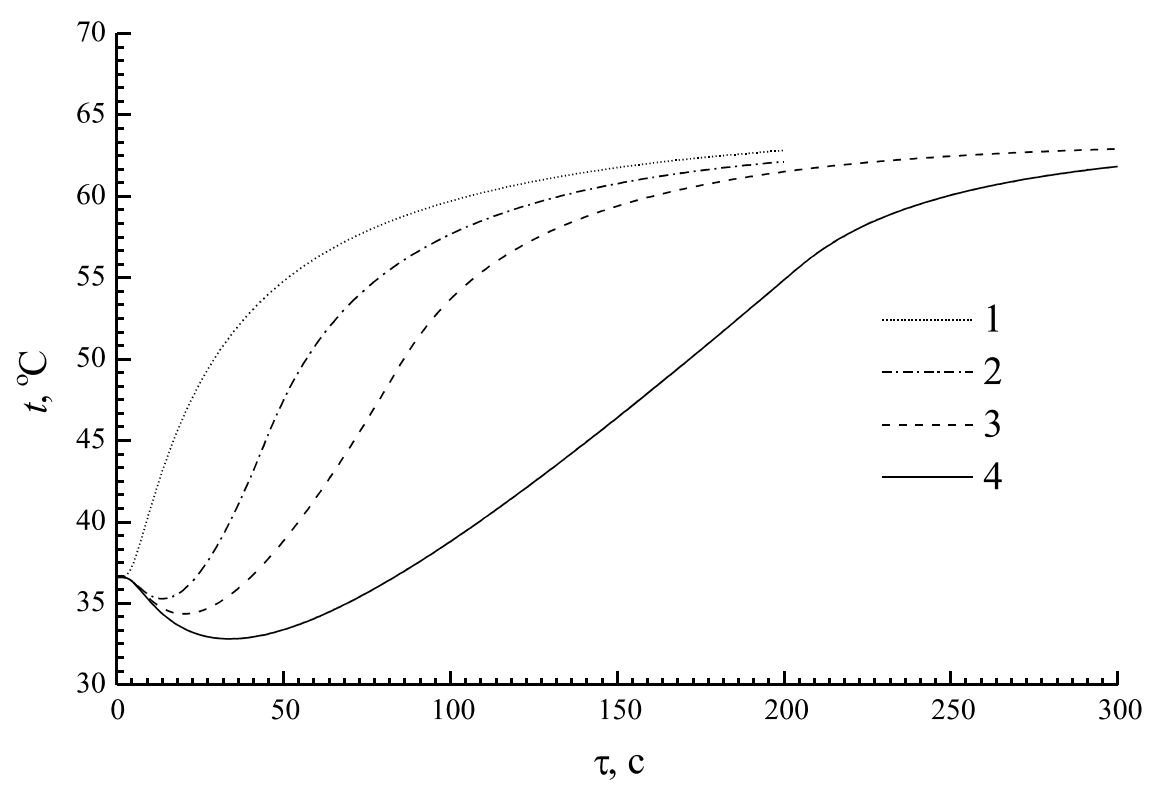

Рис. 4. Динамика изменения температуры $t$ на границе «киста - жировая ткань» для различных времен воздействия $\tau_{c}: 1-0 \mathrm{c}, 2-40 \mathrm{c}, 3-80 \mathrm{c}, 4-200 \mathrm{c}$. Здесь $\tau-$ текущее время

Согласно кинетической модели термодеградации ниже некоторой температуры $T_{\text {кр }}$ скорость накопления разрушений ничтожна, а при $T>T_{\text {кр }}$ резко возрастает с температурой. Такая графическая зависимость влияния температуры и времени нагрева на необратимое разрушение биоткани представлена в работе [Шахно, 2012]. Совместный анализ полученных нами зависимостей изменения температуры во времени на границе «киста - жировая ткань» и в области температур необратимых изменений в координатах «температура-время» показывает, что все режимы нагрева, представленные на рис. 4, удовлетворяют условиям исходной задачи. Действительно, изменение температуры от 57 до $58{ }^{\circ} \mathrm{C}$ в рассмотренных случаях происходит примерно за 10 секунд. Кроме того, температура в жировой ткани на расстоянии 2-3 мм от места контакта с кистой (см. рис. 3) не превышает безопасных $45^{\circ} \mathrm{C}$.

Однако режим нагрева со временем воздействия 200 секунд оказался наиболее предпочтительным по следующим причинам. Во-первых, в этом режиме наиболее точно выполняется условие равномерного нагрева жидкости по всему объему, поскольку, как известно, в небольших замкнутых областях конвективный теплообмен затруднен. Во-вторых, наиболее точно выполняется условие равенства температур термонесущей жидкости и поверхности кисты. В-третьих, время достижения критических температур в биотканях практически совпадает со временем воздействия, которое может быть теоретически оценено по формуле (3) и проконтролировано в реальных условиях нагрева. 
Теперь произведем оценку теплового потока от нагреваемой жидкости через внутреннюю поверхность стенки кисты к окружающей ее жировой ткани. В качестве модели полости кисты возьмем трехосный эллипсоид с тремя осями $a, b$ и $c$, исходящими из общего центра, объем и площадь поверхности которого определяются соотношениями

$$
V=\frac{4 \pi}{3} a b c, S=4 \pi\left(\frac{a^{n} b^{n}+a^{n} c^{n}+b^{n} c^{n}}{3}\right)^{\frac{1}{n}} \text {, где } n=1.6075 .
$$

Аналогичный способ уже неоднократно применялся в медицинских исследованиях как отечественных, так и зарубежных ученых [Sternberg, 2013; Бокерия, 2013].

Размеры модели полости и площадь ее внутренней поверхности определим исходя из объема вводимой жидкости и экспериментальных представлений о форме кисты Бейкера. Результаты расчетов для 3-х заданных объемов вводимой термонесущей жидкости представлены в таблице 3.

Таблица 3. Геометрические параметры модели внутренней полости кисты, соответствующие объемам вводимой термонесущей жидкости

\begin{tabular}{|c|c|c|c|c|}
\hline$V, \mathrm{~cm}^{3}$ & $2 a, \mathrm{~cm}$ & $2 b, \mathrm{~cm}$ & $2 c, \mathrm{cM}$ & $S, \mathrm{~cm}^{2}$ \\
\hline 2 & 3 & 1.6 & 0.8 & 9.6 \\
\hline 5 & 4 & 2 & 1.2 & 16.9 \\
\hline 10 & 5 & 3 & 1.3 & 28.9 \\
\hline
\end{tabular}

На рис. 5 представлены результаты расчетов теплового потока через внутреннюю стенку кисты с объемом термонесущей жидкости 2 мл и площадью поверхности 9.6 cм$^{2}$ для 3-х значений подводимой удельной мощности $P_{m}$.

Видно, что во всех случаях тепловой поток за время воздействия возрастает практически линейно, а затем быстро убывает до значения $\sim 1$ Вт. Этот тепловой поток равен минимальной мощности лазерного излучения, которую необходимо подводить к термонесущей жидкости после окончания времени основного воздействия для поддержания постоянной температуры $T_{c o g}$.

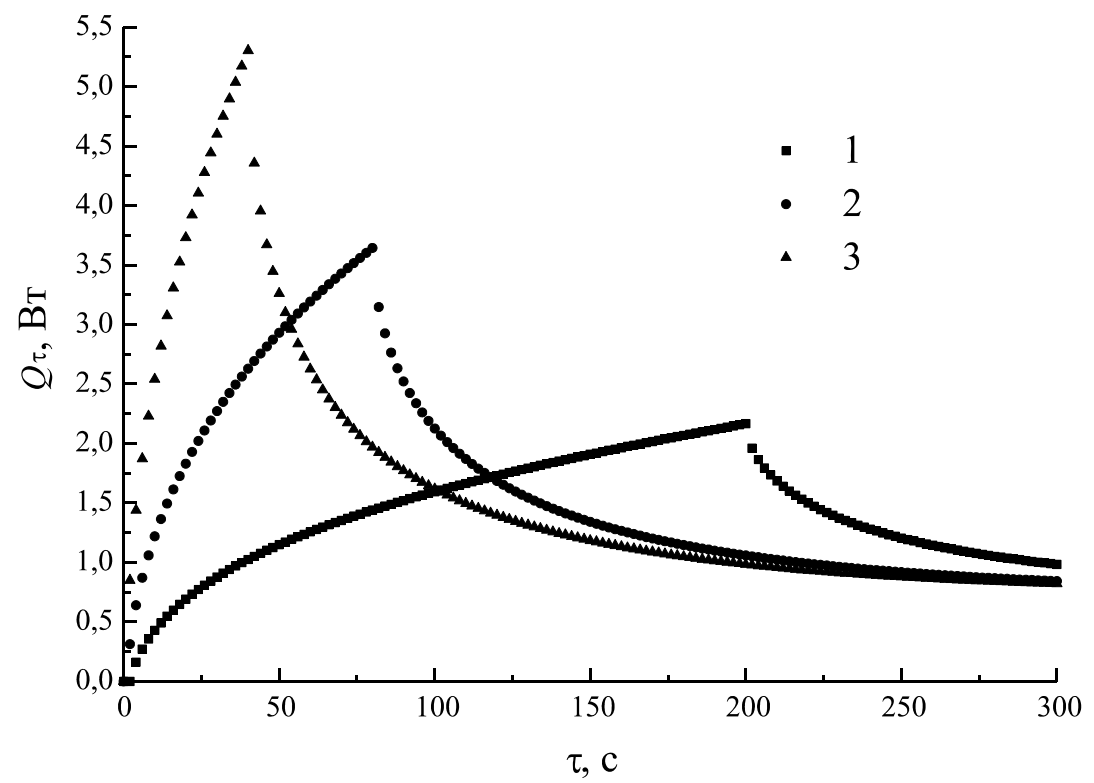

Рис. 5. Изменение теплового потока $Q_{\tau}$ во времени $\tau$ через внутреннюю стенку кисты при различных скоростях нагрева термонесущей жидкости до температуры $70{ }^{\circ} \mathrm{C}: 1-P_{m}=1 \mathrm{BT} / \Gamma\left(\tau_{\mathrm{c}}=200 \mathrm{c}\right)$, $2-P_{m}=2.5 \mathrm{BT} / \Gamma\left(\tau_{\mathrm{c}}=80 \mathrm{c}\right), 3-P_{m}=5 \mathrm{BT} / \Gamma\left(\tau_{\mathrm{c}}=40 \mathrm{c}\right)$ 
Расчеты показывают, что средний тепловой поток $\left\langle Q_{\tau}\right\rangle$ в стенку кисты для представленных на рис. 4 режимов нагрева соответственно равен: $1-1.4$ Вт, $2-2.3$ Вт, $3-3.1$ Вт.

Понятно, что в реальных условиях одностороннего нагрева для реализации тех же самых времен воздействия подводимая мощность лазерного излучения должна быть увеличена на данную величину.

В заключение отметим, что более активное внедрение в хирургическую практику термической модификации патологически измененных тканей тормозит отсутствие научного обоснования выбранного режима нагрева для конкретной ткани и клинической ситуации. Текущие рекомендации являются эмпирически подобранными, что значительно снижает эффективность процедуры и увеличивает риски нежелательных явлений или даже ятрогений. Параметры гипертермии должны не только обеспечивать достижение целевого эффекта - денатурации ткани-мишени, но и минимизировать побочные эффекты, связанные с перегревом перифокальных структур.

Результаты наших оценок пространственно-временных распределений температуры в системе «киста - жировая ткань» показывает, что наиболее полно всем требованиям исходной задачи удовлетворяет режим нагрева, в котором время воздействия составляет примерно 200 секунд. Исходя из данной рекомендации, возможно произвести расчет необходимой мощности лазерного излучения и объема термонесущей жидкости.

Таким образом, цель этого теоретического эксперимента с термодинамическими процессами, возникающими при одностороннем равномерном нагреве соединительных тканей кисты Бейкера, достигнута. Предложенная математическая модель позволяет рассчитать пространственно-временное распределение температуры в системе «киста - жировая ткань» и оценить необходимые энергетические и экспозиционные параметры при одностороннем тепловом воздействии на биоткани.

\section{Список литературы (References)}

Беляев Н. М., Рядно А. А. Методы теории теплопроводности. Ч. 2. - М.: Высшая школа, 1982. - $304 \mathrm{c}$.

Beljaev N. M., Rjadno A. A. Methods of the theory of heat conduction. Part 2 [Metody teorii teploprovodnosti. Ch. 2.]. - Moscow: High school [Vysshaja shkola], 1982. — 304 p. (in Russian).

Бокерия Л. А., Филатов А. Г., Ковалев А. С. Сравнительный анализ эффективности расширенной радиочастотной аблации зон функционального субстрата при различных формах фибрилляции предсердий // Анналы аритмологии. - 2013. - Т. 10, № 2.

Bokerija L. A., Filatov A. G., Kovalev A. S. Comparative analysis of the effectiveness of extended radiofrequency ablation of functional substrate zones for various forms of atrial fibrillation [Sravnitel'nyj analiz jeffektivnosti rasshirennoj radiochastotnoj ablacii zon funkcional'nogo substrata pri razlichnyh formah fibrilljacii predserdij] // Annals of arrhythmology [Annaly aritmologii]. — 2013. — Vol. 10, No. 2 (in Russian).

Галиулин М. Я., Халдин С. В., Худяков И. С., Анчугова А. Е., Мирошкина О. Н. Особенности лазероиндуцированной внутритканевой термотерапии в эксперименте и в клинике // Вестник Совета молодых ученых и специалистов Челябинской области. - 2016. - Т. 3, № 4 (15).

Galiulin M. Ya., Haldin S. V., Hudjakov I. S., Anchugova A. E., Miroshkina O. N. Features of laser-induced interstitial thermotherapy in the experiment and in the clinic [Osobennosti lazerinducirovannoj vnutritkanevoj termoterapii v jeksperimente i v klinike] // Bulletin of the Council of Young Scientists and Specialists of the Chelyabinsk Region [Vestnik Soveta molodyh uchjonyh i specialistov Cheljabinskoj oblasti]. — 2016. — Vol. 3, No. 4 (15) (in Russian).

Гарюк Г. И., Гарюк О. Г., Харченко Е. И., Лукашов И. Н., Ляшенко А. М. Метод локальной гипотермии в лечении вазомоторных ринитов // Міжнародний медичний журнал. - 2016. № 22, № 1. - С. $81-86$.

Garjuk G. I., Garjuk O. G., Harchenko E. I., Lukashov I. N., Ljashenko A. M. Method of local hypothermia in the treatment of vasomotor rhinitis [Metod lokal'noj gipotermii v lechenii vazomotornyh rinitov] // International Medical Journal [Mizhnarodnij medichnij zhurnal]. — 2016. — No. 22, No. 1. — P. 81-86 (in Russian). 
Петровский Б. В. Большая медицинская энциклопедия. - 1974. — Т. 14. — С. 334-338. Petrovsky B. V. Great Medical Encyclopedia [Bol'shaja medicinskaja jenciklopedija]. — 1974. — Vol. 14. — P. 334338 (in Russian).

Сапожников A. М. Хирургическое лечение повреждений и некоторых заболеваний мягких элементов коленного сустава: автореф. дис. ... канд. мед. наук / А. М. Сапожников; Виницкий медицинский институт им. И. И. Пирогова. — Винница, 1972. — 17 с.

Sapozhnikov A. M. Surgical treatment of injuries and some diseases of soft knee joint elements [Hirurgicheskoe lechenie povrezhdenij i nekotoryh zabolevanij mjagkih jelementov kolennogo sustava]: author's abstract. dis. ... cand. medical science [Avtoref. dis. ... kand. med.nauk] / A. M. Sapozhnikov; Vinickij medicinskij institut im. I. I. Pirogova. - Vinnica, 1972. — 17 p. (in Russian).

Чудновский В. М., Юсупов В.И., Захаркина О. Л., Игнатьева Н. Ю., Жигарьков В. С., Яикин М. Н., Баграташвили В. Н. Вклад лазероиндуцированной газопарожидкостной динамики в механизм эндовенозной лазерной облитерации // Современные технологии в медицине. - 2016. - Т. 8, № 2 .

Chudnovsky V.M., Yusupov V.I., Zaharkina O. L., Ignat'eva N.Yu., Zhigar'kov V.S., Yashkin M. N., Bagratashvili $V$. N. The contribution of laser-induced gas-vapor-liquid dynamics to the mechanism of endovenous laser obliteration [Vklad lazeroinducirovannoj gazoparozhidkostnoj dinamiki $\mathrm{v}$ mehanizm jendovenoznoj lazernoj obliteracii] // Modern technologies in medicine [Sovremennye tehnologii v medicine]. — 2016. — Vol. 8, No. 2 (in Russian).

Шахно Е. А. Физические основы применения лазеров в медицине: учебное пособие. - СПб.: НИУ ИТМО, 2012. - 129 с.

Shahno E. A. The physical basis of the use of lasers in medicine [Fizicheskie osnovy primenenija lazerov v medicine]: Tutorial [Uchebnoe posobie]. — Sankt-Petersburg: NIU ITMO, 2012. — 129 p. (in Russian).

Determination of the Factors In fluencing Rupture of Baker's Cystsin the Kneeon Plain Radiographsand MRI JKSMRM 16(3): 217-225, 2012.

Kumar R. PET-Based Interventions, An Issue of PET Clinics, E-Book. - Elsevier Health Sciences, 2016. - Vol. 10, No. 4.

Mahmudovich $U$. O. Surgical tactics in combined injuries of the bones of facial skull according to retrospective array // European science review. - 2016. - No. 1-2.

Sternberg R. A. et al. Association between Absolute Tumor Burden and Serum Bone-Specific Alkaline Phosphatase in Canine Appendicular Osteosarcoma // Journal of Veterinary Internal Medicine. 2013. - Vol. 27, No. 4. - P. 955-963. 